\title{
BMJ Open Health system impact of COVID-19 on urban slum population of Bangladesh: a mixed-method rapid assessment study
}

\author{
Shehrin Shaila Mahmood (D) ," Md. Zahid Hasan (D) ,' A M Rumayan Hasan, ${ }^{1}$ \\ Md. Golam Rabbani (D) , ${ }^{1}$ Farzana Begum, ${ }^{1}$ Tariq Bin Yousuf, ${ }^{2}$ \\ Syed Manzoor Ahmed Hanifi, ${ }^{1}$ Daniel D Reidpath, ${ }^{1}$ Sabrina Rasheed ${ }^{1}$
}

To cite: Mahmood SS, Hasan MZ, Hasan AMR, et al. Health system impact of COVID-19 on urban slum population of Bangladesh: a mixed-method rapid assessment study. BMJ Open 2022;12:e057402. doi:10.1136/ bmjopen-2021-057402

- Prepublication history and additional supplemental material for this paper are available online. To view these files, please visit the journal online (http://dx.doi.org/10.1136/ bmjopen-2021-057402).

Received 15 September 2021 Accepted 04 February 2022

Check for updates

(c) Author(s) (or their employer(s)) 2022. Re-use permitted under CC BY-NC. No commercial re-use. See rights and permissions. Published by BMJ.

${ }^{1}$ Health Systems and Population Studies Division, icddr,b, Dhaka, Bangladesh

${ }^{2}$ Urban Resilience Project, Dhaka North City Corporation, Dhaka, Bangladesh

Correspondence to

Dr Shehrin Shaila Mahmood; shaila@icddrb.org

\section{ABSTRACT}

Objective We aimed to rapidly assess the health system impact of COVID-19 in the urban slums of Bangladesh.

\section{Design Setting and participants}

A cross-sectional survey among 476 households was conducted during October-December 2020 in five selected urban slums of Dhaka North, Dhaka South and Gazipur City Corporation. In-depth interviews with purposively selected 22 slum dwellers and key informant interviews with 16 local healthcare providers and four policymakers and technical experts were also conducted.

Outcome measures Percentage of people suffering from general illness, percentage of people suffering from chronic illness, percentage of people seeking healthcare, percentage of people seeking maternal care, health system challenges resulting from COVID-19.

Results About $12 \%$ of members suffered from general illness and 25\% reported chronic illness. Over $80 \%$ sought healthcare and the majority sought care from informal healthcare providers. $39 \%$ of the recently delivered women sought healthcare in 3 months preceding the survey. An overall reduction in healthcare use was reported during the lockdown period compared with prepandemic time. Mismanagement and inefficient use of resources were reported as challenges of health financing during the pandemic. Health information sharing was inadequate at the urban slums, resulting from the lack of community and stakeholder engagement $(51 \%$ received COVID-19related information, $49 \%$ of respondents knew about the national hotline number for COVID-19 treatment). Shortage of human resources for health was reported to be acute during the pandemic, resulting from the shortage of specialist doctors and uneven distribution of health workforce. COVID-19 test was inadequate due to the lack of adequate test facilities and stigma associated with COVID-19. Lack of strong leadership and stakeholder engagement was seen as the barriers to effective pandemic management.

Conclusion The findings of the current study are expected to support the government in tailoring interventions and allocating resources more efficiently and timely during a pandemic.

\section{INTRODUCTION}

In March 2020, COVID-19 was declared as a pandemic by the WHO pointing to the
Strengths and limitations of this study

- The greatest strength of the study is that it took a holistic approach in exploring the health system impact of COVID-19 on urban slum dwellers taking into account data from community members, healthcare providers and policy planners.

- The study was a rapid assessment capturing insights into health system impact of COVID-19, which allowed timely evidence generation during a pandemic.

- One of the limitations of the study is it was exploratory in nature, which did not allow making any causal inference.

- The study utilised the ongoing Urban Health and Demographic Surveillance System of icddr,b for its sampling frame, which may be representative of Dhaka division, but it would be difficult to generalise the results to slums in other parts of the country.

- The study was conducted over phone, which could introduce response bias in terms of capturing sensitive issues like stigma.

sustained risk of further global spread. ${ }^{1}$ To contain the spread of the virus, 'stay-at-home' orders or lockdowns were deployed across the world including Bangladesh. ${ }^{23}$ Being a developing country, the impact of this pandemic in Bangladesh was likely diverse and multisectoral. The impact on access to healthcare has been acute with challenges including fear of COVID-19 infection at health facilities ${ }^{45}$ and economic hardship due to job loss or pay cut. $^{6-9}$

The health sector in Bangladesh is underbudgeted and the per-capita expenditure on health from the government has been low, around $27 \%$ of the total health expenses (THE), ${ }^{10}$ where the out-of-pocket expenses (OOPE) have remained the major source of healthcare financing (constituting $74 \%$ of THE). ${ }^{11}$ The health service delivery in the country suffers chronically from a lack of adequate human resources, supplies, 
medicines and governance. For acute illnesses, most people sought healthcare from unqualified, informal healthcare providers, for example, drug stores, chambers of village doctors. ${ }^{12-14}$ The challenges are even greater in urban settings where access to healthcare is more complex in absence of strong public sector primary healthcare (PHC) provision. In contrast, in rural areas, there is a strong network of PHC centres run by the Ministry of Health and Family Welfare, in the urban areas, PHC falls within the remit of the Ministry of Local Government, Rural Development and Cooperatives (MOLGRDC). MOLGRDC does not have the same kind of PHC network, and PHC in urban settings is fractured and uncoordinated, with the poor linkage between the various levels of health service delivery. ${ }^{15}$

The impact of this weak urban health system mostly affects the low-income population, the majority of whom live in the urban informal settlements (slums). Additionally, there are public health concerns specific to the urban slums owing to overcrowding, unhygienic waste management and pollution. ${ }^{16}$ With the outbreak of COVID-19, an air-borne disease, the health systems impact was expected to be the greatest among the population of the urban slums. ${ }^{17}$ In addition, the ongoing economic shutdown caused by COVID-19 threatened millions of livelihoods engaged in the informal sector with little or no financial protection for healthcare. ${ }^{18}$ Unfortunately, almost 18 months into the pandemic, there remains a paucity of information about the nature and the extent of the impact, of the pandemic on health services in the urban slums. Given the nature of the spread of the disease, it is essential to understand whether and how COVID-19 affects the utilisation of health services and OOPE during the pandemic. Understanding this is particularly important if the Universal Health Coverage lead, to leave no one behind, is to be taken seriously. Timely rapid assessments of the impact on the vulnerable groups can support the government and policymakers to design and implement efficient response plans. The current paper, thus, aims to assess the health system impact of COVID-19 on urban slum dwellers in Dhaka city.

\section{METHODOLOGY \\ Conceptual framework}

We explored the impact of COVID-19 and the resulting country-wide lockdown on the urban health system of Bangladesh through the lens of WHO's six health system building blocks (i.e., service delivery, health workforce, health information system, essential medicine, health financing, leadership/governance).$^{19}$ We explored how far health services were accessible and available to the urban slum population; challenges faced by the urban healthcare providers and the viewpoint of health policymakers towards healthcare provision in urban slums of Dhaka city during the pandemic. Figure 1 illustrates the impact pathway guiding the study.

\section{Study design and setting}

An exploratory study design applying both quantitative and qualitative approaches was used. The quantitative approach included a cross-sectional household survey. We used the sampling frame of an existing Urban Health and Demographic Surveillance System (UHDSS) of icddr,b. The UHDSS covers about 31577 households in five slums of Dhaka North, Dhaka South and Gazipur City Corporations. ${ }^{20}$ We conducted interviews with adult male and female members (aged between 18 and 80 years) of the randomly selected household of the UHDSS. The inclusion criteria were 'households who are covered under the UHDSS in the selected slums', 'households who have an active mobile phone number' and 'households who were residing at the study slum during COVID1-19 pandemic and 'households who were interested to participate in our study'. Whereas, the exclusion criteria included 'households who are not included in UHDSS', 'households who do not have an active mobile phone number', 'households who left the slum before or at the beginning

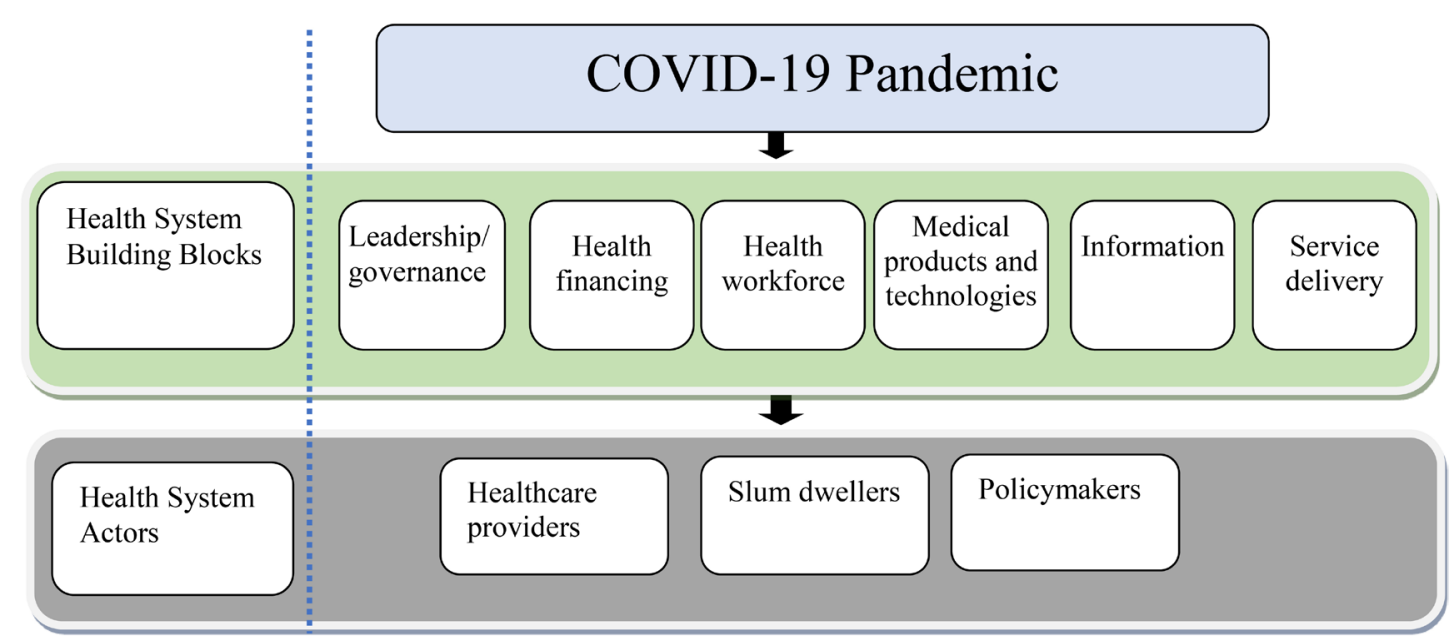

Figure 1 Health system impact of COVID-19 on urban slum dwellers. 
of pandemic' and 'households who were not interested to participate in our study'.

The qualitative approach included In-Depth Interviews (IDI) with adult male and female slum dwellers, Key Informant Interviews (KII) with healthcare providers providing healthcare to slum dwellers and with nationallevel health policymakers and technical experts.

\section{Sample size}

A recent study conducted in the urban slums of Dhaka, Bangladesh found that $41 \%$ of the respondents had an unwillingness to attend regular health services fearing COVID-19 infection and unavailability of doctors. ${ }^{21}$ We assumed that $50 \%$ of the slum population will, for similar reasons, not utilise formal healthcare during the COVID-19 pandemic for general illnesses. Using this proportion $(\mathrm{p}=0.5)$, with $95 \%$ confidence level and $5 \%$ precision level, an estimated 384 households were required for interview. Assuming a 10\% non-response rate and 1.2 design effect for five slums, 512 households matching the inclusion criteria were selected from the database of UHDSS. However, 476 households were finally interviewed (response rate 93\%). For qualitative data, a total of 22 IDIs with purposively selected male $(\mathrm{n}=10)$ and female $(\mathrm{n}=12)$ slum dwellers and 20 KIIs with purposively selected healthcare providers $(n=16)$ from local drug stores and public healthcare facilities, and national-level policymakers and technical experts $(n=4)$ were conducted.

\section{Data collection}

The household survey was conducted in five slums of UHDSS, namely, Korail, Mirpur, Shyampur, Dholpur and Ershadnagar from 31 October till 1 December 2020. We interviewed the respondents over the phone since the faceto-face interview was not feasible during the pandemic. During their routine data collection, the UHDSS surveillance workers took verbal consent over the phone from the households and healthcare providers regarding their participation in the current study. Only households agreeing to share their mobile numbers were included in the sampling frame for the survey. Household survey data were collected using an android-based electronic questionnaire. Qualitative interviews with community members, healthcare providers and national-level policy planners were conducted by phone till 15 January 2021.

\section{Study instrument}

Trained data collectors administered a pretested household survey in Bangla. Respondents were provided BDT 200 (US\$2.37) using a mobile financial service compensating for their time spent participating in the study. The survey collected information on household members' latest episode of general illness, healthcare-seeking behaviour and expenditure during the 14 days preceding the survey and respondents' access to COVID-19-related information, 90 days preceding the survey for Maternal, Newborn and Child Health (MNCH) services and 12 months preceding the survey for one major chronic illness, e.g., diabetes, arthritis, asthma, cardiovascular disease and hypertension. The IDIs with the slum dwellers explored their access to healthcare during pandemic, information related to COVID-19 and challenges they faced in accessing healthcare. The KIIs with the healthcare providers and the policymakers sought their opinion and suggestions about the seven out of eight pillars of health system preparedness to respond to the COVID-19 pandemic, including (1) coordination, planning and monitoring; (2) risk communication and community engagement; (3) surveillance, rapid response and case investigation; (4) laboratories; (5) infection prevention and control; (6) case management; (7) operational support and logistics. ${ }^{22}$ During the data collection phase of the study, the national COVID-19 vaccination programme was yet to initiate in the country, which limited the scope of the current study to comment on all but one pillar (i.e., vaccination) of health system preparedness.

\section{Statistical analysis}

The characteristics of households and respondents are presented as categorical variables with frequency (n) and percentage $(\%)$. The median OOPE is presented in BDT (US $\$ 1=\mathrm{BDT}$ 83). Health service utilisation, source of care and OOPE have been compared with the findings from previous urban health surveys and health surveillance data. Quantitative analyses were performed using Stata, V.14. ${ }^{23}$

A systematic framework approach was used for analysing the qualitative data. On completion of an IDI or KII, verbatim transcriptions were made. The transcripts were then read carefully and matched with the records to determine missing information and divided under different themes and codes. We generated a matrix using the categories derived from different themes and subthemes. The findings under each main theme, subthemes or category were presented for the identification of key areas of interest. Triangulation of information was done for validating the findings obtained from different sources.

\section{Patient and public involvement}

Patients or the public were not involved in the design, or conduct, or reporting or dissemination plans of our research.

\section{RESULTS}

\section{Sociodemographic and economic information of the study} households and the household members

We surveyed 476 households with a total of 2140 members. The proportion of male and female members was almost equal. About $32 \%$ of household members had no education. More than half of the members were married (53\%). About $67 \%$ of members were currently unemployed. The highest proportion of the members belonged to the poorest quintile (27\%) and about $21 \%$ belonged to the richest asset quintile (table 1). 
Table 1 Background characteristics of household members $(\mathrm{N}=2140)$

\begin{tabular}{lcc}
\hline Variables & $\mathbf{n}$ & $\%$ \\
\hline Age in years & & \\
\hline$\leq 14$ & 631 & 29.5 \\
\hline $15-29$ & 682 & 31.9 \\
\hline $30-39$ & 349 & 16.3 \\
\hline $40-49$ & 224 & 10.5 \\
\hline $50-59$ & 131 & 6.1 \\
\hline 60 & 123 & 5.8 \\
\hline Sex & & \\
\hline Male & 1064 & 49.7 \\
\hline Female & 1076 & 50.3 \\
\hline Education level & & \\
\hline No education & 680 & 31.8 \\
\hline Primary & 701 & 32.8 \\
\hline Secondary and above & 759 & 35.5 \\
\hline Occupation & & \\
\hline Currently unemployed & 1442 & 67.38 \\
\hline Service holder & 261 & 12.20 \\
\hline Businessman & 115 & 5.37 \\
\hline Informal worker & 299 & 13.97 \\
\hline Others & 23 & 1.07 \\
\hline Marital status & & \\
\hline Married & 1641 & 76.7 \\
\hline Unmarried & 52.8 \\
\hline Others & 36.3 \\
\hline Regular earning person & & \\
\hline Yes & & \\
\hline No & & \\
\hline Househo. & & \\
\hline
\end{tabular}

\section{Household income in last 30 days}

\begin{tabular}{lll} 
No income & 546 & 25.5 \\
$\leq 8000$ & 352 & 16.5 \\
\hline $8001-14000$ & 557 & 26.0 \\
\hline $14001-20000$ & 362 & 16.9 \\
\hline 20000 & 323 & 15.1 \\
\hline Asset quintiles & & \\
\hline Poorest & 572 & 26.7 \\
\hline Second & 279 & 13.0 \\
\hline Third & 405 & 18.9 \\
\hline Fourth & 433 & 20.2 \\
\hline Richest & 451 & 21.1 \\
\hline
\end{tabular}

Impact of COVID-19 on urban health systems

Health service delivery

Healthcare utilisation

About 12\% of the members suffered from general illness in the last 14 days preceding the survey and $83 \%$ of them recovered from their illness by the day of the interview (table 2). The majority suffered from cough (33\%), followed by fever $(32 \%)$, pain/chest pain $(12 \%)$ and
Table 2 Healthcare utilisation for general illness or symptoms in 14 days

\begin{tabular}{lrr}
\hline Variables & $\mathbf{n}$ & $\%$ \\
\hline $\begin{array}{l}\text { Suffered from general illness or } \\
\text { symptoms }\end{array}$ & 251 & \\
\hline Yes & 1889 & 88.3 \\
\hline No & & \\
\hline Has the person recovered now? & 207 & 82.5 \\
\hline Yes & 44 & 17.5 \\
\hline No & & \\
\hline Self-reported illness/symptoms & 83 & 33.1 \\
\hline Cough & 81 & 32.3 \\
\hline Fever & 31 & 12.4 \\
\hline Pain/chest pain & 11 & 4.4 \\
\hline Diarrhoea & 10 & 4.0 \\
\hline Skin disease & 6 & 2.4 \\
\hline Weakness & 5 & 2.0 \\
\hline Shortness of breath & 5 & 2.0 \\
\hline Injury/fractured & 19 & 7.6 \\
\hline Others (e.g., vomiting, worms) & 227 & 90.4 \\
\hline Did the person receive any treatment? & & 9.6 \\
\hline Yes & & \\
\hline No & & \\
\hline
\end{tabular}

\section{Reason for not seeking treatment} (multiple response)

\begin{tabular}{lrr} 
The problem was not critical & 14 & 51.9 \\
\hline Financial constraints & 8 & 29.6 \\
\hline Fear of COVID-19 & 3 & 11.1 \\
\hline Others & 5 & 7.4
\end{tabular}

\section{How long after the onset of illness} was treatment sought?

\begin{tabular}{lrc} 
The day the person got sick & 27 & 11.9 \\
One day later & 114 & 50.2 \\
\hline Two days later & 52 & 22.9 \\
Three or more days later & 34 & 15.0 \\
Source of healthcare utilisation. & & \\
Drug stores & 145 & 63.9 \\
\hline Private hospitals & 37 & 16.3 \\
\hline Public hospitals & 31 & 13.7 \\
NGO hospitals & 5 & 2.2 \\
Others (e.g., homeopathic) & 9 & 4 \\
\hline
\end{tabular}

NGO, Non-Governmental Organization.

diarrhoea (4\%). About $90 \%$ of those reporting illnesses, sought healthcare mostly from the local drug stores $(64 \%)$ followed by private hospitals $(16 \%)$ and public hospitals $(14 \%)$.

About $25 \%$ of individuals aged 40 years and above reported suffering from a chronic illness (table 3). Most of them suffered from diabetes $(24 \%)$ followed by 
Table 3 Chronic illness and healthcare utilisation among the households' members aged 40 and above

\begin{tabular}{lcc}
\hline Variables & $\mathbf{n}$ & $\%$ \\
\hline Suffered any chronic illness & & \\
Yes & 120 & 25.1 \\
\hline No & 358 & 74.9 \\
\hline Type of chronic disease & & \\
\hline Diabetes & 29 & 24.2 \\
\hline Arthritis & 24 & 20.0 \\
\hline Asthma & 19 & 15.8 \\
\hline Cardiovascular disease & 16 & 13.3 \\
\hline Hypertension & 11 & 9.2 \\
\hline Psychological disorder & 4 & 3.3 \\
\hline Chronic Ovarian disease & 3 & 2.5 \\
\hline Liver disease & 3 & 2.5 \\
\hline Others (e.g., gastric, prolonged injury) & 11 & 9.2 \\
\hline
\end{tabular}

Have to take regular treatment for this disease.

\begin{tabular}{lll} 
Yes & 96 & 80.0 \\
\hline No & 24 & 20.0 \\
\hline $\begin{array}{l}\text { Sought treatment for this disease in last } \\
\text { 3 months }\end{array}$ & \\
\hline Yes & 67 & 55.8 \\
No & 53 & 44.2 \\
\hline
\end{tabular}

Reasons for not not seeking treatment (multiple response)

\begin{tabular}{lrr} 
The problem was not critical & 28 & 41.8 \\
\hline Financial constraint & 25 & 37.3 \\
\hline Fear of COVID-19 & 12 & 17.9 \\
\hline Others (e.g., no accompanying person) & 3 & 3.0 \\
\hline Source of healthcare utilisation. & & \\
\hline Public hospital & 15 & 22.4 \\
\hline Private hospital & 18 & 26.9 \\
\hline drug store & 31 & 46.3 \\
\hline Others (e.g., homeopathic) & 3 & 4.5 \\
\hline
\end{tabular}

arthritis (20\%), asthma (16\%), cardiovascular (13\%) and hypertension $(9 \%)$. About $80 \%$ regularly sought treatment for chronic illness. More than half of the members with chronic illness $(56 \%)$ had received treatment in the 3 months preceding the interview. Local drug stores were again the major source of treatment $(46 \%)$. About $37 \%$ of the members suffering from chronic illness did not seek care due to financial constraints and around $18 \%$ refrained from seeking care due to fear of COVID-19 infection.

The respondents of the qualitative interviews also spoke about more service utilisation from informal providers during the pandemic compared with other times. Patients with COVID-19 like symptoms feared being identified and stigmatised as patients with COVID-19 and referral to high-cost health facilities for treatment, if they were seeking treatment at a formal health facility. The cost of formal healthcare was also an important deciding factor for using informal providers.

During the first two months, I received many patients with different health problems along with breathing difficulties. We usually suggest general drugs for breathing difficulty (drug vendor, KII-2).

Among the mothers who utilised healthcare in the year preceding the survey, $39 \%$ of them sought healthcare in 3 months period (table 4). Of the 27 mothers reporting $\mathrm{MNCH}$ care utilisation about half reported using antenatal care (ANC), 30\% used delivery care and $21 \%$ reported utilising postnatal care (PNC) services. The majority of the ANC services were sought from private facilities and Non-Governmental Organization (NGO) clinics. Eight out of total 10 deliveries reported were normal deliveries of which about $38 \%(n=3)$ took place at home. Whereas, 7 out of $10(70 \%)$ deliveries were institutional of which about $29 \%(n=2)$ were caesarean section and the majority of them took place at private facilities $(n=4)$. PNC services were availed only by those who had institutional deliveries.

\section{Healthcare provision}

An overall reduction in healthcare utilisation was reported by urban healthcare providers during the pandemic compared with prepandemic period. From the healthcare providers, we found that the number of home deliveries in urban slums of Dhaka city increased and the number of normal deliveries also increased at the facilities. Many mothers tried to deliver their babies at home with assistance from Traditional Birth Attendants (TBAs) but came to the facilities when TBAs could not help.

Normal delivery at our hospital decreased during lockdown. We learned that they (pregnant women) tried to have normal delivery at home. They fell at risk. Traditional birth attendants are not trained to manage complications. We dealt with mothers who experienced complications after home delivery during lockdown (physician, KII-7).

\section{Challenges in health service delivery during pandemic}

In the context of COVID-19, both service recipients and service providers faced challenges in accessing and providing services. Respondents from the community spoke about reduced hours of the formal health facilities, shortage of doctors as they were deployed to manage the pandemic, unavailability of specialists as they stopped attending, lack of physical examination and requirement of COVID-19 tests were some of the major barriers to access healthcare during pandemic.

The healthcare providers talked about the lack of a triage system at the health facilities to identify patients with COVID-19 symptoms, an initial shortage of personal protective equipment (PPE), challenges in maintaining proper safety measures, an increased workload and stress 
Table 4 Utilisation of maternity care (child delivery and pregnancy-related)

\begin{tabular}{lrr}
\hline Variables & $\mathbf{n}$ & $\%$ \\
\hline $\begin{array}{l}\text { Sought maternity healthcare last year } \\
\text { (delivery and pregnancy-related) }\end{array}$ & & \\
\hline Yes & 69 & 13.4 \\
\hline No & 445 & 86.6 \\
\hline
\end{tabular}

\section{Sought maternity healthcare in last 3 months (delivery and pregnancy-related)}

\begin{tabular}{lrr} 
Yes & 27 & 39.1 \\
\hline No & 42 & 60.9 \\
\hline $\begin{array}{l}\text { Reasons for not seeking treatment (multiple } \\
\text { response) }\end{array}$ & & \\
\hline $\begin{array}{l}\text { The problem was not critical } \\
\text { Financial constraint }\end{array}$ & 76 & 73.5 \\
\hline Fear of COVID-19 & 3 & 14.3 \\
\hline Others (e.g., distance) & 3 & 6.1 \\
\hline
\end{tabular}

\section{Maternity care received in last 3 months} (multiple services)

$\begin{array}{lrr}\text { ANC } & 16 & 48.5 \\ \text { Delivery } & 10 & 30.3 \\ \text { PNC } & 7 & 21.2\end{array}$

\section{Number of ANC}

\begin{tabular}{|c|c|c|}
\hline Less or equal to three times & 12 & 75.0 \\
\hline Four times plus & 4 & 25.0 \\
\hline \multicolumn{3}{|l|}{ Source of ANC care } \\
\hline Public hospital & 1 & 6.3 \\
\hline Private hospital & 7 & 43.8 \\
\hline NGO hospital & 7 & 43.8 \\
\hline Others (e.g., trained birth attendant) & 1 & 6.3 \\
\hline \multicolumn{3}{|l|}{ Type of delivery } \\
\hline Normal delivery & 8 & 80.0 \\
\hline Caesarean delivery & 2 & 20.0 \\
\hline \multicolumn{3}{|l|}{ Place of delivery } \\
\hline Home delivery & 3 & 30.0 \\
\hline Institutional delivery & 7 & 70.0 \\
\hline \multicolumn{3}{|l|}{ Source of delivery care } \\
\hline Public hospital & 2 & 28.5 \\
\hline Private hospital & 4 & 57.1 \\
\hline NGO hospital & 1 & 14.3 \\
\hline \multicolumn{3}{|l|}{ Number of PNC } \\
\hline One time & 4 & 57.1 \\
\hline More than one time & 3 & 42.9 \\
\hline \multicolumn{3}{|l|}{ Source of PNC } \\
\hline Public hospital & 2 & 28.6 \\
\hline Private hospital & 3 & 42.9 \\
\hline NGO hospital & 1 & 14.3 \\
\hline Others & 1 & 14.3 \\
\hline
\end{tabular}

ANC, antenatal care; NGO, Non-Governmental Organization; PNC, postnatal care. among the major challenges they faced in providing healthcare during the pandemic.

\section{Healthcare financing}

In terms of budget allocated to manage the pandemic, the policymaker and the technical expert group members mentioned that the government with support from development partners was able to mobilise resources to manage the pandemic. However, there were challenges in ensuring efficient use of the resources. The inefficiency was more visible in Dhaka city where the pandemic response strategy was rather rapid but unplanned. As mentioned by one respondent:

In Dhaka city, there was urgency and thus there was mismanagement. As we heard, people involved in the ministry of health and family welfare tried to release the fund which was in each of the operation plans of different departments, and they could do it. Later the government received funds from the donor agency. This was enough resource for the health sector..... It will not be correct to say resource shortage hindered the implementation of activities to manage the pandemic (technical expert, KII-19).

During discussions about the reasons for inefficiency related to spending existing resources, respondents talked about existing government financial rules as an important barrier for rapid spending of money during the pandemic. As one respondent said:

A lot of money was misused ...you must have read in newspapers during pandemic.... I am not sure whether it was adequate or not but there was not any lack of funds. To some extent, they could not spend money due to the financial rules... (technical expert, KII-17).

\section{Out of pocket expense for healthcare during pandemic}

The median total OOPE per patient for treating general illness was BDT 315 in the 14-day preceding the survey. About $96 \%$ of the care seekers required medicine for which the median expenditure on medicine was BDT 300. In the 3 months preceding the survey, the median OOPE for chronic illness was BDT 1750 . For MNCH care-related expenditure in the 3 months preceding the survey, we found that 16 eligible mothers who took ANC incurred a median OOPE of BDT 1220. Most of the expenditure was related to medical components, e.g., medicine, diagnostic, etc. The median OOPE for delivery $(n=10)$ was BDT 4360. Total seven mothers who took PNC services had a median OOPE of BDT 760 (figure 2).

\section{Health information on COVID-19 prevention, management and} treatment

Around $51 \%$ of the respondents mentioned receiving COVID-19-related messages in the 30 days preceding the survey. The rest reported not receiving any message. Fifty-one per cent of the respondents were not aware of 


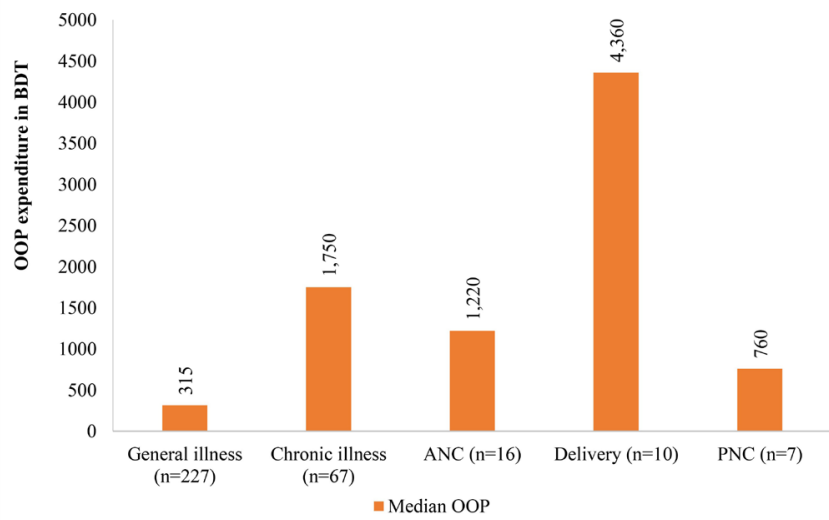

Figure 2 Median out-of-pocket expenditure for healthcare. ANC, antenatal care; OOP, out-of-pocket; PNC, postnatal care.

the national hotline number that provides COVID-19related treatment through telemedicine (table 5).

Television was the major source of COVID-19-related information for respondents $(75 \%)$ followed by neighbours $(6.5 \%)$ and social media $(5.5 \%)$ (figure 3 ).

The lack of access to COVID-19-related information in the general population was also reported by the members of national technical committee for COVID-19 (KII respondents). The respondents mentioned that, although the government took several prevention initiatives, many of them were not effectively implemented. The experts from the technical committee concluded that engaging community in prevention, health education and awareness-raising, to contain the spreading of the virus, was important; however, the government initiative to engage the community was inadequate. This was in contrast to the government officials we interviewed. One respondent said:

DG [Directorate General] health is not so active in engaging community in preventive intervention but they are working. Bureau of health communication is also working with NGOs in this regard. However, this is not enough for effective engagement of community in pandemic management (technical expert, KII-19).

Table 5 Knowledge about access to COVID-19-related information

\begin{tabular}{lcc}
\hline Variables & Yes; n (\%) & No; n (\%) \\
\hline $\begin{array}{l}\text { Do you have access to quarantine } \\
\text { facility nearby your house/ workplace? }\end{array}$ & $94(19.8)$ & $382(80.25)$ \\
$\begin{array}{l}\text { Did you receive any message on } \\
\text { COVID-19 prevention and treatment? }\end{array}$ & $244(51.26)$ & $232(48.74)$ \\
$\begin{array}{l}\text { Do you know any hotline number to } \\
\text { contact in case of any symptoms of you } \\
\text { or others? }\end{array}$ & $234(49.16)$ & $242(50.84)$ \\
\hline
\end{tabular}

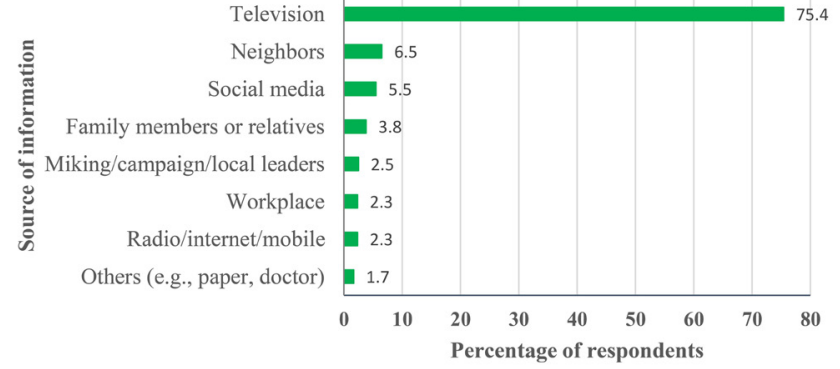

Figure 3 Source of information on COVID-19.

\section{Health workforce}

Our findings indicate that the existing shortage of human resources in health in Bangladesh became more acute in both public and private health facilities during the pandemic. This was due to the unavailability of senior physicians to attend general patients during the lockdown period and the reassignment of physicians to attend patients with COVID-19. One respondent said:

[The] Majority of the senior, experienced and specialized physicians did not attend patients. Frontline health workers had to face the battle (technical expert, KII-18).

Deployment of Human Resources (HRs) to tackle patients with COVID-19 also resulted in a shortage of HR in service delivery areas for general patients. The respondents also expressed their concern about the concentration of doctors and nurses in Dhaka city to deal with the burden of the pandemic. One respondent said:

Government has taken some good initiatives in response to Covid-19. You know the government has recruited and deployed more than 2000 physicians and many other health staff on an urgent basis. But there has been a problem in posting those physicians. The physicians have not been posted at places where they are originally planned for. Due to political pressure ..., many of them have been placed in urban areas or district level (technical expert, KII-17).

Safety of both patients and healthcare providers was another source of concern expressed. They highlighted the absence of a triage system at the entry point of health facilities to be a major obstacle in ensuring patient and provider safety from COVID-19 infection. One respondent said:

In our facility, two staff members had been infected and we all had to go for isolation for 14 days. Therefore, there was no one to operate our facility. People have not received any treatment from our facility at that time (physicians, KII-1).

Moreover, the respondents stated that there was a lack of a standard incentive package from the government to 
cover the health risks faced by frontline health workers, which led to discontent among the health workers.

\section{Medical products and technologies}

The respondents from the slums stated that access to existing COVID-19 test facilities was challenging for the urban slum dwellers due to the long waiting hours to get tested at public facilities which were affordable for them and the high cost of the testing at the private facilities.

Many of our patients do not want to do the Corona test. The private diagnostic facilities have high charges for the test which the poor patients cannot afford. It is true that testing at public facilities is a hassle. Many of our patients shared their experience that they have to stand in a long queue and wait for a long time to get tested and then the reports take a long time. One patient told me that he received his report after 15 days of giving sample (healthcare provider, KII-1).

There was, moreover, a general lack of interest among slum dwellers to get tested because of the stigma associated with testing positive for COVID-19 and the accompanying fear of losing one's job.

They do not want to go for doing COVID-19 test. If we refer them, they do not want to go because they fear that the hospital will admit them and will not allow them to meet with their family members. Community people would avoid them after knowing that they got infected. Thus, they do not want to get the test done (healthcare provider, KII-04).

Moreover, according to the technical experts who were interviewed, the limited number of testing facilities resulted in limited availability of tests in the early stages of the pandemic. Not only there were fewer testing centres but also the slum dwellers were not aware of the testing centres. One of the technical experts held the view that:

The lower-class people always experience discrimination. They are always deprived and in terms of getting COVID-19 related health services, they have been deprived (technical expert, KII-17).

\section{Leadership/governance}

A lack of strong leadership and strategic planning at the central level of the government was identified as one of the major health system challenges during the pandemic by the technical experts. Centralisation of decisionmaking was seen as a barrier to the timely allocation and use of resources in managing local challenges posed by the pandemic. One respondent said:

All decisions are made by one or two people. The WHO suggested involving all people in relevant sectors in order to fight with the pandemic. This is not possible for the ministry of health independently. Not all divisions of the government were involved. Things could have been different if all sectors worked together (technical expert, KII-19).
Online supplemental table 1 presents an overview of the opinions of all the technical experts and the healthcare providers in relation to the health system impact of COVID-19 pandemic (online supplemental table 1).

\section{DISCUSSION}

The study findings highlight the effect of the COVID-19 pandemic and the resulting country-wide lockdown on the health systems of Bangladesh from the perspective of health service users and providers in urban slums as well as policymakers and members of the national technical committee on COVID-19. The impact on the six different building blocks of health systems is presented in the study $^{19}$ (online supplemental table 1 ).

Before pandemic, a study conducted in urban slums of Dhaka city in 2017 reported that $93 \%$ of patients suffering from chronic illness sought treatment. ${ }^{20}$ Findings from our study showed that healthcare seeking was adversely affected in the urban slums during the pandemic, particularly for patients suffering from chronic illness $(37 \%$ lower). The lower use of ANC, PNC, general outpatient services and immunisation services was also reported in a study conducted by USAID. ${ }^{24}$

One important finding is the rise in the demand for informal healthcare providers during the pandemic period by slum dwellers; consistent with the finding of other studies conducted in similar settings. ${ }^{25}{ }^{26}$ The utilisation of health services provided by formal health facilities was limited during this time due to such issues as shortened service hours, lack of physicians, COVID-19 test requirements at the hospitals and financial constraints. Two other studies also reported that financial constraints and fear of COVID-19 infection acting as barriers to accessing healthcare. ${ }^{27} 28$ Unfortunately, the increased use of informal healthcare providers including the traditional birth attendants puts patients at higher risk of malpractice. Healthcare providers from the NGO-run clinics reported dealing with complicated maternity cases that had been unsuccessfully managed by unskilled providers.

The health system also faced challenges from the limited supplies including PPE, shortage of human resources, lack of screening mechanism to isolate patients with COVID-19 from general patients, and the workload and stress of healthcare providers. Due to the lack of a triage system at the entry point of health facilities in urban areas, the healthcare providers and general patients were always at risk of getting infected. The vulnerability of frontline healthcare providers during the pandemic has also been reported elsewhere. ${ }^{25}{ }^{29}$ In an effort to protect both patients and healthcare providers, the system could benefit from establishing an easier triage system at the entry point of all health facilities to separate patients presenting with COVID-19 like symptoms from the rest. In addition, for certain health conditions, the use of remote healthcare through telehealth services could prove to be crucial in ensuring that patients get healthcare without compromising their own safety or that of 
the healthcare providers. The national telehealth service, Shastho Batayon (16263), was in operation during the pandemic; however, its reach was found to be limited in the urban slums with only $49 \%$ of slum dwellers knowing about the service.

Earlier studies have shown community engagement to be a crucial part of many health initiatives ${ }^{30} 31$ including initiatives for the management of communicable diseases ${ }^{32}$ and maternal and child health conditions. ${ }^{33}$ More recently community engagement has been considered as a fundamental component during outbreaks, such as the Ebola epidemic in 2014-2015 in West Africa. ${ }^{34}{ }^{35}$ There was an overall lack of penetration of government initiatives for raising awareness within the urban slum areas, and $49 \%$ of the respondents mentioned not receiving any COVID-19-related information in the 3 months preceding the survey. This could be explained by the low level of community engagement activities of the government in managing the pandemic. In managing the COVID-19 pandemic, the urban health system needed to have expanded programmes to engage community members effectively. In its absence, it is difficult to ensure universal coverage of services. Studies published on COVID-19 have also highlighted the importance of community engagement for COVID-19 prevention and control. ${ }^{30} 3637$

The health system of Bangladesh suffers chronically from a shortage of human resources for health. ${ }^{38}$ This shortage became more acute during the pandemic when a higher number of doctors had to be placed at COVID-19 specialised hospitals to manage the sudden surge in cases. As a consequence, there was a lack of adequate healthcare providers to treat general patients at other health facilities. Furthermore, for their personal safety, and being among the high-risk group for COVID-19, senior and specialised doctors stopped providing services or switched to teleconsultation during the pandemic. In some places, service hours were shortened. In combination, these changes to the health system hindered access to routine care and in many cases delayed healthcare seeking for patients in urban Dhaka. The lack of physicians or general patients during pandemic has also been reported elsewhere. ${ }^{2425}$

Delayed healthcare seeking has far-reaching health implications, which can lead to increased complications and longer and more intensive treatment. This is expected to have both health and financial consequence on the population. The government of Bangladesh deployed an additional 2500 doctors and 5000 nurses on ad hoc basis as a rapid response to the pandemic. ${ }^{39}$ It started in June 2020, which assisted the health system to gradually resume the other essential health services in the country.

According to the findings, healthcare financing for pandemic management in Bangladesh suffered more from inefficient planning and implementation rather than the lack of available funds. The urgent requirement for fund disbursement, the centralised financial management, the lack of efficient fund allocation mechanism during an emergency and political influence all hindered the efficient use of available resources to manage the pandemic. From a user's perspective, the average OOPE for acute illness was found to be BDT 350 per patient, which was higher than the average OOPE for urban slum dwellers reported in a study conducted in the prepandemic period (BDT 280 per patient). ${ }^{20}$ This higher OOPE may be attributable to the unavailability of formal healthcare providers during the COVID-19 period and increased referrals to the higher cost formal providers. In order to ensure the financial protection of slum dwellers, the social safety net programmes of the government should be extended to include the urban slum population. Health protection schemes need to be developed and implemented to ensure universal health coverage during and after the pandemic.

According to the technical experts interviewed, the urban health system was not adequately equipped to deal with the pandemic. Initially, there were very few test centres for COVID-19, although the number increased over time. The public test centres were affordable and were overwhelmed with patients, resulting in long waiting times. The private centres were easier to access but unaffordable for the urban slum dwellers. In addition to the cost and time considerations, the study identified stigma associated with COVID-19 to be a major reason for a lack of interest in testing among the slum dwellers of Dhaka city. Earlier studies conducted on the urban poor population of Bangladesh have reported lower test rates among lower socioeconomic classes and the stigma associate with COVID-19 discouraging people from getting tested. ${ }^{25} 26$

Finally, the study findings highlighted some challenges and loopholes in the national planning that would require interventions from the various levels of the government and civil society. The study identified a lack of coordination between the stakeholders from different sectors of the health system (eg, public, private, NGOs) as a major challenge in managing the pandemic. ${ }^{40}$ Although NGOs with their extensive engagement at the grassroots level took up independent initiatives to support the urban slum dwellers during the pandemic, ${ }^{26}{ }^{41}$ their engagement in the planning and implementation of government initiatives was negligible. Furthermore, the lack of coordination between the different departments of urban health has been a long-standing challenge for the urban health system. ${ }^{42}$

\section{CONCLUSIONS}

The health system of Bangladesh is overburdened. Therefore, good governance and leadership are needed in managing urban health during this pandemic. The adverse effect of the pandemic has been acute on the health system, which warrants the need for effective 
planning and sustained investment in building a resilient health system for the country, particularly the urban health system. The government of Bangladesh and other developing countries should take initiatives to document all challenges of the health system faced during the pandemic and the best practices to overcome the challenges. This will eventually help develop an effective pandemic preparedness plan that is contextualised for the country settings and prepares the health system to tackle future health emergencies.

Acknowledgements icddr,b acknowledges with gratitude the commitment of Swedish International Development Cooperation Agency (Sida) to its research efforts and funding for this study. icddr,b is also thankful to the Government of Bangladesh, Canada, Sweden and the UK for providing core/unrestricted support.

Contributors SSM and DDR contributed to conceptualising the research idea and study design and are the guarantor for the overall content of the manuscript. SSM, $\mathrm{MZH}, \mathrm{AMRH}$ conducted data analysis, writing, revising and finalising the manuscript with the support of MGR, FB, TBY, SMAH, DDR and SR. All authors read, revised and approved the final version of the manuscript.

Funding This manuscript was produced with the support of Sida (Grant Number: GR-01455). Views expressed in this paper do not necessarily reflect the views of the Sida authority.

Competing interests None declared.

Patient consent for publication Not applicable.

Ethics approval This study involves human participants and was approved by Institutional Review Board of icddr,b (protocol number: PR-200143). Participants gave informed consent to participate in the study before taking part.

Provenance and peer review Not commissioned; externally peer reviewed.

Data availability statement Data are available upon reasonable request. The dataset generated and/or analyzed during the current study is not publicly available. However, it is available from the corresponding author on reasonable request following icddr,b data sharing policy.

Supplemental material This content has been supplied by the author(s). It has not been vetted by BMJ Publishing Group Limited (BMJ) and may not have been peer-reviewed. Any opinions or recommendations discussed are solely those of the author(s) and are not endorsed by BMJ. BMJ disclaims all liability and responsibility arising from any reliance placed on the content. Where the content includes any translated material, BMJ does not warrant the accuracy and reliability of the translations (including but not limited to local regulations, clinical guidelines, terminology, drug names and drug dosages), and is not responsible for any error and/or omissions arising from translation and adaptation or otherwise.

Open access This is an open access article distributed in accordance with the Creative Commons Attribution Non Commercial (CC BY-NC 4.0) license, which permits others to distribute, remix, adapt, build upon this work non-commercially, and license their derivative works on different terms, provided the original work is properly cited, appropriate credit is given, any changes made indicated, and the use is non-commercial. See: http://creativecommons.org/licenses/by-nc/4.0/.

\section{ORCID iDs}

Shehrin Shaila Mahmood http://orcid.org/0000-0002-6546-9120

Md. Zahid Hasan http://orcid.org/0000-0002-3824-8947

Md. Golam Rabbani http://orcid.org/0000-0003-3166-0397

\section{REFERENCES}

1 WHO. Coronavirus disease 2019 (COVID-19) Situation Report-51, 2020. Available: https://www.who.int/emergencies/diseases/novelcoronavirus-2019

2 Flaxman S, Mishra S, Gandy A, et al. Estimating the effects of non-pharmaceutical interventions on COVID-19 in Europe. Nature 2020;584:257-61.

3 The Goverment of Bangladesh. Government of Bangladesh cabinet fighting with coronavirus: press briefing of cabinet Secretary. Dhaka, 2020. https://cabinet.gov.bd/sites/default/files/files/cabinet.portal. gov.bd/notices/9abbd38f_f012_401c_a172_4654fc2ffada/corona press briefing.pdf

4 The Daily Prothom Alo. Fear and stigma in the context of corona epidemic in Bangladesh, 2020. Available: https://en.prothomalo. com/opinion/analysis/fear-and-stigma-in-the-context-of-coronaepidemic-in-bangladesh

5 The daily Dhaka Tribune. Covid-19: fear leads hospitals to reject dying asthma patients, 2020. Available: https://www.dhakatribune. $\mathrm{com} /$ health/coronavirus/2020/06/09/covid-19-fear-leads-hospitalsto-reject-dying-asthma-patients

6 Rahman HZ, Matin I. Rapid response survey: poverty impact of COVID-19. Dhaka, 2020. Available: https://www.pprc-bd.org/pprccovid-19-response/

7 Siddiquee MSH, Faruk A. COVID-19's Impact on Bangladesh Economy. Dhaka, 2020. Available: https://bigd.bracu.ac.bd/wpcontent/uploads/2021/01/Working-Paper_COVID-19s-Impact-onBangladesh-Economy.pdf

8 Rahman HZet al. Livelihoods, coping and recovery during COVID-19 crisis Livelihoods, coping and recovery during COVID-19 crisis. Dhaka, 2020.

9 Khan H. Economic impact of COVID-19 on Bangladesh: agenda for immediate action and planning for the future. Dhaka, 2020. Available: https://mpra.ub.uni-muenchen.de/100380/

10 MOHFW. Bangladesh National health accounts 1997-2015. Dhaka, 2017.

11 The World Bank. Out-of-pocket expenditure (\% of current health expenditure) - Bangladesh, 2021. Available: https://data.worldbank. org/indicator/SH.XPD.OOPC.CH.ZS? locations=BD [Accessed 4 Jul 2021].

12 Billah SM, Hoque DME, Rahman M, et al. Feasibility of engaging "Village Doctors" in the Community-based Integrated Management of Childhood Illness (C-IMCI): experience from rural Bangladesh. $J$ Glob Health 2018:8:20413.

13 Mahmood SS, Iqbal M, Hanifi SMA, et al. Are 'Village Doctors' in Bangladesh a curse or a blessing? BMC Int Health Hum Rights 2010;10:18.

14 Bloom G, Standing $\mathrm{H}$, Lucas $\mathrm{H}$, et al. Making health markets work better for poor people: the case of informal providers. Health Policy Plan 2011;26(Suppl 1):i45-52.

15 Govindaraj R, Raju D, Secci F. Health and nutrition in urban Bangladesh: social determinants and health sector governance. Washington, DC: The World Bank, 2018.

16 Razzaque A, Chowdhury R, Mustafa AG. Making slums visible: studying slums and their dynamics in Urban Bangladesh. In: Hossain MM, Majumder MAH, Chin B, et al., eds. Slum health in Bangladesh: insights from health and demographic surveillance. Dhaka: icddr,b Special Publication, 2019.

17 Rejve K, Iqbal MJ. COVID-19: Bangladesh Multi-Sectoral anticipatory impact and needs analysis. Dhaka 2020.

18 World Economic Forum. Why Bangladesh is especially vulnerable to the coronavirus 2020.

19 WHO. Everybody's business-strengthening health systems to improve health outcomes: WHO's framework for action. Geneva, Switzerland, 2007. Available: https://www.who.int/healthsystems/ strategy/everybodys_business.pdf

20 Hossain. Slum health in Bangladesh: insights from. Dhaka: Health and Demographic Surveillance, 2019. http://dspace.icddrb.org/jspui/ bitstream/123456789/9298/1/icddrb-SP154.pdf

21 Ria AF, Raha SA, Rana S. Exploring the impact of covid-19 on adolescents in urban slums in Dhaka, Bangladesh. Dhaka 2020.

22 WHO. COVID-19 strategic preparedness and response plan operational; planning guidelines to support country preparedness and response WHO, 2020.

23 StataCorp. Stata statistical software: release 142016.

24 USAID. Estimating the effect of COVID-19 on total utilization of health services in Bangladesh 2021.

25 CARE Bangladesh. COVID-19 : Bangladesh Multi-Sectoral Anticipatory Impact and Needs Analysis Needs Assessment Working Group Date : Needs Assessment Working Group, 2020. Available: https://reliefweb.int/sites/reliefweb.int/files/resources/covid_nawg_ anticipatory_impacts_and_needs_analysis.pdf

26 Barkat A, Ahamed F, Mamun M. Socio-Economic assessment of COVID-19 under national urban poverty reduction program. Dhaka, Bangladesh, 2020. https://www.undp.org/content/dam/undp/library/ covid19/undp-bd-Socio-EconomicAssessmentCOVID-19-2021.pdf

27 Sakamoto M, Begum S, Ahmed T. Vulnerabilities to COVID-19 in Bangladesh and a reconsideration of sustainable development goals. Sustainability 2020;12:5296-15.

28 CARE, UNOPS and Uk. COVID-19 : Bangladesh Multi-Sectoral Anticipatory Impact and Needs Analysis Needs Assessment Working Group Date : Needs Assessment Working Group 2020. 
29 Swazo NK, Talukder MMH, Ahsan MK. A duty to treat? A right to refrain? Bangladeshi physicians in moral dilemma during COVID-19. Philos Ethics Humanit Med 2020;15:1-23.

30 Gilmore B, Ndejjo R, Tchetchia A, et al. Community engagement for COVID-19 prevention and control: a rapid evidence synthesis. BMJ Glob Health 2020;5:e003188.

31 Marston C, Renedo A, Miles S. Community participation is crucial in a pandemic. Lancet 2020;395:1676-8.

32 Questa K, Das M, King R, et al. Community engagement interventions for communicable disease control in low- and lowermiddle-income countries: evidence from a review of systematic reviews. Int J Equity Health 2020;19:1-20.

33 Kuruvilla S, Bustreo F, Kuo T, et al. The global strategy for women's, children's and adolescents' health (2016-2030): a roadmap based on evidence and country experience. Bull World Health Organ 2016;94:398-400.

34 Gillespie AM, Obregon R, El Asawi R, et al. Social mobilization and community engagement central to the Ebola response in West Africa: lessons for future public health emergencies. Glob Health Sci Pract 2016;4:626-46

35 Carter SE, O'Reilly M, Frith-Powell J, et al. Treatment seeking and Ebola community care centers in Sierra Leone: a qualitative study. $J$ Health Commun 2017;22:66-71.
36 Shi Y, Jiang H-L, Yang M-X, et al. The precision of epidemiological investigation of COVID-19 transmission in Shanghai, China. Infect Dis Poverty 2021;10:1-3.

37 UN High Commissioner for Refugees (UNHCR). Risk communication and community engagement (RCCE) - COVID-19, 2020: 1-9. https:// www.refworld.org/docid/5e84a8874.html

38 WHO. Global health workforce alliance: Bangladesh, 2021: 1-6. https://www.who.int/workforcealliance/countries/bgd/en/

39 WHO. Bangladesh gradually resumes essential health services delivery disrupted due to the COVID-19 pandemic, 2021: 1-6. https://www.who.int/bangladesh/news/detail/24-12-2020 bangladesh-gradually-resumes-essential-health-services-deliverydisrupted-due-to-the-covid-19-pandemic

40 Shammi M, Bodrud-Doza M, Towfiqul Islam ARM, et al. COVID-19 pandemic, socioeconomic crisis and human stress in resourcelimited settings: a case from Bangladesh. Heliyon 2020;6:e04063.

41 The World Bank Group. Global responses to COVID-19 in slums and cities: practices from around the world, 2020: 1-120. http://pubdocs. worldbank.org/en/829971589899181351/May15-Response-toCOVID-in-Slums-and-Cities.pdf

42 Asian Development Bank. Local government institutional assessment. Dhaka, Bangladesh: Urban Primary Health Care Services Delivery Project, 2015. https://www.adb.org/sites/default/files/linkeddocuments/42177-013-ban-oth-03.pdf 